\title{
TRABAJO INFANTIL Y POBREZA DE LOS HOGARES en la Argentina
}

\author{
Jorge A. Paz y Carolina Piselli**
}

Fecha de recepción: 10 de diciembre de 2010. Fecha de aceptación: 11 de mayo de 2011.

\begin{abstract}
RESUMEN
El modelo de Basu y Van (1998) plantea a nivel teórico la llamada hipótesis de lujo según la cual los hogares están comandados por padres altruistas y pobres que recurren al trabajo infantil como estrategia de escape de la pobreza. Según este enfoque, si la economía está en una situación de equilibrio múltiple, puede ocurrir que la aplicación efectiva de las leyes que prohíben el trabajo infantil provoque un empeoramiento del bienestar de los hogares y aumente la pobreza. Con datos de la Encuesta de Actividades de Nińos, Nińas y Adolescentes realizada en la Argentina en 2004, se explora empíricamente la hipótesis de padres altruistas examinando en qué medida la pobreza monetaria y las privaciones materiales pueden considerarse determinantes de la participación económica de niñas, niños y adolescentes.
\end{abstract}

Palabras clave: Trabajo infantil, pobreza, Argentina, infancia y niñez.

\section{Child labor and household poverty in Argentina}

\begin{abstract}
The model of Basu and Van (1998) presents, at a theoretical level, the so-called luxury hypothesis, according to which households are headed by altruistic and poor parents who recur to child labor as a strategy to escape poverty. This focus states that if the economy is in a situation of multiple equilibrium, it may happen that the effective application of laws prohibiting child labor lead to a worsening of household welfare and an increase in poverty. Using data from the Activities of Boys, Girls and Adolescents carried out in Argentina in 2004, we explore empirically the altruistic parent hypothesis, examining how monetary poverty and material privation can be considered determinants of economic participation by girls, boys and adolescents.
\end{abstract}

Key words: Child labor, poverty, Argentina, infancy and childhood.

* Investigador del Consejo Nacional de Investigaciones Científicas y Técnicas (CONICET) con sede en el Instituto de Estudios Laborales y del Desarrollo Económico (IELDE), Facultad de Ciencias Económicas, Universidad Nacional de Salta. Correo electrónico: jpaz@conicet.gov.ar

** Investigadora del IELDE, Facultad de Ciencias Económicas, Universidad Nacional de Salta. Correo electrónico: caro.piselli@gmail.com 
Jorge A. Paz y Carolina Piselli

\section{TRAVAIL DES ENFANTS ET PAUVRETÉ DES FOYERS EN ARGENTINE}

\section{Résumé}

Le modèle de Basu et Van (1998) établit au niveau théorique la dénommée hypothèse de luxe selon laquelle les foyers sont commandés par des parents altruistes et pauvres qui recourent au travail de leurs enfants comme stratégie pour échapper à la pauvreté. Selon cette approche, si l'économie est dans une situation d'équilibre multiple, il peut arriver que l'application effective des lois qui interdisent le travail des enfants empire la qualité de vie des foyers et augmente la pauvreté. Sur la base de données de l'Enquête sur les activités d'enfants et adolescents (Encuesta de Actividades de Niños, Niñas y Adolescentes) réalisée en Argentine en 2004, l'hypothèse de parents altruistes est explorée empiriquement en examinant dans quelle mesure la pauvreté des revenus et les privations matérielles peuvent être vues comme déterminants dans la participation économique d'enfants et d'adolescents.

Mots clés : travail des enfants, pauvreté, Argentine, enfance.

\section{O TRABALHO INFANTIL E A POBREZA DOS LARES NA ARGENTINA Resumo}

O modelo de Basu e Van (1998) assume a nível teórico a chamada hipótese de luxo, segundo La qual os lares estáo comandados por pais altruístas e pobres que recorrem ao trabalho infantil como estratégia de escapar da pobreza. Segundo este enfoque, se a economia esta em uma situação de equilíbrio múltiplo, pode ocorrer que a aplicação efetiva das leis que proíbem o trabalho infantil provoque uma piora do bem-estar dos lares e aumente a pobreza. Com dados da Pesquisa de Atividades de Crianças e Adolescentes realizada na Argentina em 2004, se explora empiricamente a hipótese de pais altruístas examinando em que medida a pobreza monetária e as privaçóes materiais podem ser consideradas determinantes da participaçáo econômica de crianças e adolescentes.

Palavras-chave: Trabalho infantil, pobreza, Argentina, infância.

\section{阿根廷的童工及家庭贫困}

小结

巴苏和范(1998) 的模式提出一个理论设想, 叫做豪华设想, 根绝这个设 想，所有的家庭不是在有着利他主义思想的家长的领导下，就是在那些指 望通过童工来摆脱贫困的贫穷家长的领导下。根据这一点, 如果经济是 在一种多重平衡的情况下, 那么法律是能够有效而广泛的禁止少年儿童工 作，进而来防止家庭福利的日渐下降和贫困的增长。在2004年对阿根廷的 青少年活动的一项民意测验中, 通过对贫穷程度和物质䘏之程度的调查, 凭借经验能够探索出利他主义父母的设想猜测, 物质上的匮乏被认为是决 定青少年参与经济活动的主要决定因素。

关键词：童工，贫困，阿根廷，青少年时期 


\section{INTRODUCCIÓN}

En el debate acerca de las causas del trabajo infantil, la pobreza del hogar figura como un determinante crucial. El modelo desarrollado por Basu y Van (1998) lo plantea como un axioma: los padres mandarán a sus hijos a trabajar si el ingreso por ellos generado (por los adultos) no resulta suficiente para superar el umbral de la supervivencia. La verificación empírica del axioma de padres altruistas (llamada también "hipótesis del lujo", HL) tendría claras consecuencias en el diseño y formulación de políticas públicas orientadas a reducir y/o erradicar el trabajo infantil. Por ejemplo, la aplicación estricta de leyes de prohibición del trabajo de niñas, niños y adolescentes (NNyA) conduciría a algunos hogares a la pobreza; ${ }^{1}$ aunque, por otro lado, podría suceder que una política de inserción al mercado laboral de los adultos en edades centrales -más la observancia de algunas regulaciones laborales (salarios mínimos por ejemplo)- desembocaría en la reducción de la incidencia del trabajo de nNyA.

Ahora bien, de no verificarse empíricamente la HL, las políticas y los programas dirigidos a la pobreza (por ejemplo las transferencias monetarias condicionadas, las estrategias de reducción de la pobreza, etcétera), no tendrían el efecto esperado en la incidencia del trabajo infantil y adolescente. Tampoco deberían preocupar las consecuencias de las crisis económicas en esta dimensión; ni las recuperaciones post-crisis deberían generar expectativas de reducción del porcentaje de nNyA que se dedican a actividades económicas. De esto se desprende que el estudio de la relación entre la pobreza de los hogares y el trabajo de NNyA dista mucho de ser trivial.

El sustento lógico del modelo de Basu y Van (1998) es muy sólido, pero la evidencia empírica no es concluyente al respecto. ${ }^{2}$ Algunas pruebas recientes basadas en un concepto más amplio de altruismo paterno (Schluter y Whaba, 2008) se aproximan a una idea similar a la planteada en el modelo teórico; pero el tema central de la discusión (cuán sensible es la tasa de actividad de NNyA a la pobreza de los hogares) no está cerrado.

1 Claro está que para que esta situación se produzca es necesario que trabajo infantil y trabajo adulto no sean factores sustitutos en la producción. Un axioma más del esquema teórico de Basu y Van (1998), el axioma de la complementariedad/sustituibilidad (o viceversa), considera esta importante relación.

2 La evidencia empírica es voluminosa. La más pertinente será examinada con cierto detalle en más adelante en este documento. 
El trabajo infantil es una categoría social que no puede ser fácilmente capturada por las encuestas a hogares comunes. Muchas de las actividades realizadas por NNyA permanecen ocultas a las formas usuales de medición que se basan en el concepto de "trabajo remunerado" como la definición dominante de "trabajo". En general, todos los procesos generadores de valor que carecen de precios de mercado enfrentan idénticos problemas. La sola prohibición explícita de contratar NNyA juega como un incentivo a la no declaración. A esto se suma las características propias de actividades que por definición no aparecen como "actividades económicas" y que, por lo tanto, se escapan de los dispositivos de medición tradicionales.

Éstas son algunas de las razones que han conducido a los países a promover y desarrollar estrategias diferentes de obtención de datos como las encuestas sobre usos del tiempo y las de trabajo infantil. Precisamente en este estudio se utiliza la Encuesta de Actividades de Niños, Niñas y Adolescentes (EANNA) realizada en la Argentina en el año 2004, para examinar la relación entre los ingresos del hogar y la propensión de los NNyA de realizar algún tipo de trabajo, ya sea para el mercado, para el autoconsumo o para el hogar.

A partir de la EANNA se conoce hoy en la Argentina mucho más sobre trabajo infantil. Se sabe por ejemplo que la tasa de actividad de los que tienen entre 5 y 13 años ronda el 6.5\%; mientras que la del grupo de adolescentes (entre 14 y 17 años de edad), el 20\% aproximadamente. Se sabe también que existe una acentuada disparidad por género no sólo en el nivel de la participación, sino en el tipo de tareas realizadas por varones y por mujeres (Waisgrais, 2007a). También se conoce la importancia relativa de determinantes tales como la edad y el nivel educativo de los padres (Torre, 2008) y las consecuencias del trabajo infantil para la acumulación normal de capital humano (Waisgrais, 2007b).

No obstante la relación entre el ingreso familiar y la participación de menores no fue lo suficientemente analizada; o al menos no lo fue con la importancia que el tema merece a juzgar por el lugar que ocupa en la literatura internacional. Los no muy abundantes modelos teóricos de trabajo infantil (Basu y Van, 1998; Brown, 2006), y algunos estudios empíricos ya tradicionales sobre el tema (Ray, 2000; Kambhampati y Rajan, 2005; Schluter y Whaba, 2008), adjudican a la pobreza del hogar buena parte de la responsabilidad de la entrada de los niños al mercado laboral. ${ }^{3}$ Justamente la presente investigación intenta dar una respuesta al interrogante central: ¿ Es la pobreza de los hogares un determinante crucial de

3 El problema reside en el tipo de modelo que se selecciona para interpretar los comportamientos de los miembros de las familias. El modelo de Basu y Van (1998) supone padres altruistas. El ocio y la educación de nińas y niños aparecen como argumentos de sus funciones de utilidad con derivadas parciales positivas y decrecientes. 
la participación de NNyA? Por "determinante crucial" se entiende aquí altamente significativo e independiente de los demás factores relacionados tanto con la pobreza como con el trabajo infantil.

El artículo ha sido organizado según el siguiente plan. En la próxima sección se revisa la literatura más estrechamente ligada al problema bajo análisis: la relación entre la pobreza del hogar y la actividad económica de NNyA. En la sección siguiente se presenta la fuente de datos usada y la metodología de análisis elegida para el tratamiento de la información. En la sección IV se discuten los principales hallazgos del estudio poniendo énfasis en sus implicancias para la política pública. La sección $v$ resume lo encontrado a lo largo del estudio. El documento contiene además un apéndice de cuadros.

\section{LITERATURA}

Quizá la frase que mejor expresa la inquietud que se indaga en este documento es la de un trabajo publicado por la Oficina Internacional del Trabajo: "Las niñas y niños trabajadores forman parte, en su gran mayoría, de hogares en condición de pobreza (insuficiencia de ingresos). La motivación del trabajo infantil responde entonces en buena medida a esa situación y a la necesidad de generar ingresos para el hogar" (Sauma, 2007). Es decir, se parte de una afirmación que si bien resulta intuitivamente plausible, cuenta con escaso respaldo empírico.

De los 12 trabajos incluidos en la Tabla 5 de Kambhampati y Rajan (2005), 6 arrojan evidencia favorable a la LH y 6 no logran validarla. De estos últimos podría decirse que se reparten por mitades entre los que no encuentran asociación alguna, y los que se manifiestan a favor de una relación no lineal entre ingresos familiares y trabajo infantil y adolescente (en algunos casos especificando que se trata de un perfil "U-invertida”). En Perú y Pakistán, Ray (2000) no encuentra significancia estadística que respalde la LH en ninguno de los países. Además, mientras en Perú hay respaldo a la hipótesis de sustitución ( $\mathrm{sH}$ ), en Pakistán parece haber complementariedad entre el trabajo infantil y el trabajo adulto femenino, por lo tanto es primordial diferenciar entre el trabajo de adultos por género a la hora de modelar la participación de niñas y niños en el mercado laboral. Esta literatura sugiere también agregar en las regresiones indicadores de infraestructura que incrementan la participación escolar y desalientan la laboral, en ambos países.

El área rural está presente en Bhalotra y Heady (2003), quienes examinan la oferta de trabajo infantil rural a partir de un modelo de maximización de 
utilidad intertemporal del hogar y someten sus hipótesis a prueba empírica usando datos de Ghana y Pakistán. En este estudio se examina con cierto detalle la denominada "paradoja de la riqueza" o "U-invertida", que consiste en lo siguiente: por ciertas circunstancias principalmente ligadas a imperfecciones en los mercados de trabajo y tierra, las familias propietarias de parcelas para cultivar tienen claros incentivos para emplear trabajo infantil, incentivos que podrían llegar a ser más fuertes cuanto mayor sea la extensión de tierra a cultivar. Estos autores consideraron como variable dependiente las horas de trabajo infantil de las familias campesinas, incorporando además de las variables comúnmente usadas como edad, educación, composición del hogar, otras que caracterizan al sistema de organización de la producción agrícola y al consumo del hogar. Sus resultados respaldan la endogeneidad del consumo pero no de la extensión de la tierra. Sobre los comportamientos diferenciados entre el trabajo infantil femenino y masculino, Bhalotra y Heady rescatan las relaciones de sustitución del trabajo infantil de niños y niñas y el trabajo de adultos contratados. Más recientemente, Kambhampati y Rajan (2005) y Basu et al (2010) proporcionaron evidencias que operan a favor de la hipótesis de la "U-invertida".

Brown (2006) va un poco más allá que la simple inserción de los NNyA, e indaga el papel que desempeña la pobreza en las decisiones de empleo de los niños de las familias pobres. Además sugiere un modelo en el que las familias comparan el valor presente de los ingresos provenientes del trabajo infanto-juvenil con el valor futuro de los ingresos generados por la productividad aumentada vía la acumulación de capital humano y la educación formal. La tasa de descuento de las familias pobres sería muy elevada por lo que estarían otorgando una baja ponderación al ingreso futuro obtenido por sus hijos escolarizados. El sustento de esta argumentación tiene en cuenta las oportunidades que se le presentan a nNya. Muchas veces puede ocurrir que las oportunidades de empleo sean más asequibles que las de educación, por lo que los padres terminan decidiéndose a favor del trabajo y en contra de la escolarización de sus hijos. ${ }^{4}$

Otro grupo de autores rescata los problemas de endogeneidad a los que se enfrenta la investigación de este tema. La decisión de NNyA de trabajar está estrechamente vinculada al ingreso familiar y no puede ser desconectada del mismo. Podría darse el caso de una determinación simultánea que produzca algún problema en la estimación de los efectos de una variable sobre otra. Por eso es que prefieren desdoblar los ingresos ya sea por fuente (laboral/no laboral) o por

4 El origen de estas consideraciones puede hallarse en Cigno et al (2005). 
perceptor: madre o padre (Kambhampati y Rajan, 2005). En estas investigaciones se advierte que el sesgo puede ser mayor cuanto mayor sea la importancia del trabajo de NNyA en el ingreso familiar. Al respecto cabe recordar que según los datos aportados por Waisgrais (2007b), dicho aporte puede llegar a tener importancia en el caso argentino.

Más cerca de los intereses de este estudio y usando datos de la EAnNa, Torre (2008) estimó un modelo logit con el objeto de identificar las principales variables que determinan el trabajo de niñas y niños ( 5 a 13 años) en Argentina. Se incluyeron la edad, el género y la educación de los niños; la zona geográfica, las características de la vivienda, la existencia de servicios tales como agua corriente, gas natural, entre otros y del hogar, composición del hogar, nivel de educación de los padres, y cobertura de salud del jefe de hogar. La significancia estadística de los coeficientes es la teóricamente esperada. Se debe destacar que el nivel de educación es un importante determinante del trabajo infantil y queda evidente alguna relación de complementariedad entre el trabajo adulto e infantil.

Con la misma base de datos Waisgrais (2007a) mostró una sugerente relación negativa entre la participación de niños y jóvenes en el mercado laboral y el ingreso familiar. Este autor sostiene además que el trabajo infanto-juvenil tiene un efecto ostensible sobre los ingresos familiares, lo que indica que si se cumple el axioma del lujo, la estrategia de los hogares consistente en recurrir al trabajo de menores para suavizar el ingreso, cumple su cometido. El trabajo de este autor concluye que el antídoto más poderoso contra el trabajo NNyA es la educación de los padres.

En suma, si bien hay razones teóricas (al menos desde el trabajo seminal de Basu y Van, 1998) e intuitivas que sugieren fuerte asociación entre pobreza de los hogares y el trabajo de NNyA, el análisis empírico de la relación causal pobreza-trabajo infantil no es para nada concluyente y los estudios empíricos abocados al estudio de esta relación, no encuentran evidencias claras a favor de la HL. Además de los analizados en los párrafos precedentes, Edmonds (2005) plantea la no linealidad de la relación ingreso del hogar-trabajo infantil, mientras que del Río y Cumsille (2008) examinando la justificación que los padres dan acerca de la decisión de enviar sus hijos a trabajar, encuentran que si bien la necesidad económica efectivamente es el principal motor del trabajo infantil en algunos de los grupos más vulnerables de la población, las preferencias culturales tienen un peso muy importante. Quizá convenga entonces explorar otro tipo de mecanismos asociados al trabajo infantil, tales como los relacionados a la familia y cultura y su interacción con las fuerzas del mercado (Basu y Tzannatos, 2003). 
Jorge A. Paz y Carolina Piselli

\section{DATOS Y METODOLOGÍA}

Los datos usados en esta investigación provienen de la Encuesta de Actividades de Niños, Niñas y Adolescentes (EANNA) del año 2004. El origen de este relevamiento se remonta al acuerdo de 1996 entre el gobierno argentino y la Organización Internacional del Trabajo (оIт) que promovió el accionar hacia el cumplimiento de los principios y objetivos relacionados al trabajo infantil. Una de las tareas llevada a cabo por el Ministerio de Trabajo, Empleo y Seguridad Social (MTESs), la oit a través del Programa Internacional para la Erradicación del Trabajo Infantil (IPEC) y el Instituto Nacional de Estadística y Censos (INDEC), fue la realización de la EANNA.

La EANNA se ejecutó entre septiembre y diciembre de 2004 en varias jurisdicciones del país: la Ciudad de Buenos Aires y partidos del Gran Buenos Aires (Región GBA); Tucumán, Salta y Jujuy (Región NOA); Chaco y Formosa (Región NEA), y la provincia de Mendoza. Recogió información sobre las principales características de los hogares, indagando con mayor profundidad las actividades realizadas por NNyA. Utilizó tres cuestionarios: a) Características de la vivienda en la que habita el hogar; $b$ ) rasgos sociodemográficos básicos de todos los integrantes del hogar; $c$ ) información específica sobre los NNyA que integran el hogar.

Las dimensiones que agrupan las actividades de NNyA son las siguientes: a) orientadas al mercado, $b$ ) productivas para el consumo del hogar, y $c$ ) domésticas. El primer grupo incluye una amplia variedad que va desde tareas realizadas en establecimientos fabriles o comerciales, a la mendicidad, pasando por la venta callejera, el trabajo doméstico fuera del hogar y otras tareas marginales. El segundo grupo comprende actividades realizadas por NNyA para el autoconsumo: por ejemplo producción de bienes primarios, y construcción de la vivienda donde residen. El tercero está conformado por el trabajo doméstico intenso: atención de labores tales como limpieza, cocina y cuidado de personas, entre otras.

La pobreza de los hogares (y el ingreso familiar en general) está estrechamente asociada con otras características de sus miembros (bajo nivel educativo del jefe de hogar y de su cónyuge, empleo adulto poco calificado, hogares numerosos y con muchos niños, etcétera) que se relacionan también con el trabajo infantil. No prestar la debida atención a este hecho implica ignorar la posibilidad de una relación espuria entre pobreza y trabajo infantil. Es por este motivo también que un análisis puramente descriptivo puede esconder este tipo de problemas y mostrar relaciones que no existen en realidad. Es imprescindible condicionar los datos mediante el uso de alguna técnica multivariada. En este estudio se aplica la regresión logística en dos variantes: a) Modelos logísticos 
dicotómicos (MLD) para estudiar el efecto de la pobreza sobre la probabilidad de desarrollar algún tipo de actividad; $b$ ) Modelos logísticos multinomiales (MLMN) para capturar el efecto de la pobreza sobre las alternativas de actividades de NNyA: sin actividad económica, con actividad para el mercado, para el auto-consumo y para el hogar (doméstica intensa). En términos muy generales los modelos responden a la siguiente estructura:

$$
y=x \beta+u
$$

En los MLD la variable $y$ toma dos valores: 1 si la niña, niño o adolescente trabaja y 0 en caso contrario. En los MLMN, la variable $y$ toma valor 1 si la nińa, niño o adolescente trabaja para el mercado, 2 si lo hace para el autoconsumo, y 3 si realiza tareas domésticas intensas. La categoría de base es "ninguna de las anteriores" (estudia o se dedica al ocio).

En ambos casos, la matriz $\mathbf{x}$ está compuesta por una columna de unos (para incluir la ordenada en las estimaciones) y " $\mathrm{k}$ " condicionantes (o variables de control), entre los que importan los relacionados con la situación personal de NNyA (edad, sexo y asistencia escolar, por ejemplo), con el hogar (lugar de residencia, ingresos, etcétera), con las características de los padres (edad, educación, condición de actividad, etcétera) y con ciertas características geográficas (urbano/rural). De todas las variables incluidas en $\mathbf{x}$, importan particularmente las orientadas a captar el estatus de pobreza del hogar y que se detallan en el Apartado A. En el Cuadro A.1 (Apéndice) se resume la información correspondiente a las variables utilizadas y se presentan sus valores promedios. Además se muestran allí algunos detalles de construcción tales como los valores máximos y mínimos de cada una.

\section{A. Las variables dependientes}

Como variables dependientes se consideraron las actividades laborales de los niños entre 5 y 17 ańos de edad: actividad para el mercado, ${ }^{5}$ autoconsumo y doméstica intensa. La "intensidad" de la actividad doméstica se establece a partir de un umbral de horas semanales que depende de la edad del niño o joven. Dicho umbral intenta capturar cuándo el trabajo doméstico se constituye en un

5 Si bien la EANNA permite elegir lo hecho por NNyA en el año anterior y/o en la semana previa, en este estudio se optó por la segunda posibilidad. 
obstáculo severo para el desarrollo de las actividades educativas y/o de ocio a las que tienen derecho los nNya. Para esto la EANNA ha seguido los criterios establecidos en MTESS/orT (2005). ${ }^{6}$

En las regiones investigadas por la EANNA aproximadamente un $10.6 \%$ de NNyA (5-17 años de edad) realizan actividades orientadas al mercado de trabajo, $7.7 \%$ domésticas, y un $4.9 \%$ autoconsumo. Estos porcentajes difieren levemente al considerar exclusivamente las áreas urbanas: $10.3 \%$, 7.7\% y $4.2 \%$, respectivamente. Con el fin de comparar la situación de las regiones de Argentina cubiertas por la EANNA se computó la tasa de actividad de niños y niñas entre 10 y 14 años de edad que es la usada por iLo (1998) en la evaluación acerca de la situación laboral de la nińez en el mundo. La EANNA arroja una tasa de actividad del $11.9 \%$ un tanto más elevada que el promedio mundial para el año 2000 (11.2\%) y bastante más alta que la media de América Latina (8.2\%). La obtenida para las regiones cubiertas por la EANNA es similar a la de la India a principios del 2000 (12.1\%).

\section{B. Las variables independientes}

Las variables independientes que más importan para este estudio, tienen que ver con la condición de pobreza del hogar. Se usaron dos específicas: la monetaria, por un lado, y la pobreza por privación de necesidades básicas (PNB), por otro. La pobreza monetaria se computó comparando el ingreso del hogar, neto del aporte de NNyA, con los umbrales de pobreza. Éstos se marcaron usando las líneas estimadas por el INDEC para cada una de las regiones estadísticas del último trimestre del año 2004,7 lo que permitió identificar a los hogares que están en la pobreza monetaria extrema o indigencia que no alcanzan a cubrir la canasta básica alimentaria (СвA) y los que son pobres pues sus ingresos no resultan suficientes para cubrir el costo de la canasta básica total (Свт). Por su parte, la pobreza por PNB alude a privaciones en alguno (o todos) de seis indicadores de la vivienda en la que habitan los NNyA: tipo de vivienda, material de las paredes exteriores, material de los pisos, hacinamiento, disponibilidad de agua y tenencia

6 Los topes son 15 horas o más por semana para mayores de 13 años, y 10 horas semanales o más para los y las menores de 14 años.

7 El único problema fue la provincia de Mendoza, a la que se le asignaron los umbrales correspondientes a la región Cuyo del $4^{\circ}$ trimestre de 2004. 
de baño. En las regresiones se consideró la intensidad de las PNB sumando el número de ellas que presenta cada hogar. Claramente el dominio de dicha variable abarca los valores de 0 (ninguna) a 6 (todas).

Entre las variables independientes de control de NNyA se tomaron la edad, su cuadrado y el sexo. Todos los estudios sobre trabajo infantil ubican a esta última entre las variables más importantes, no sólo para entender el nivel de la actividad laboral de NNyA, sino la especificidad de la tarea desarrollada. Se han considerado también la asistencia a la escuela y el tipo de escuela a la que asiste (pública/ privada), dado que estudio y trabajo aparecen como actividades que compiten por el tiempo de nNya (Paz y Piselli, 2010), y que si la escuela es pública o privada importa no sólo por el costo de la escolaridad, sino también por la posibilidad de jornadas extendidas (doble jornada).

Se incluyeron variables de recuento del número de menores de 5 años en el hogar. En este grupo se incluyen a todos los nińos que no tienen edad de asistencia a la escuela, a pesar de la obligatoriedad del último ańo del nivel inicial impuesta por la Ley Educación Nacional (LEN: Cap. II, Art. 18). Se utilizó también un dummy con valor 1 si en el hogar algún integrante (al menos uno) aparecía como beneficiario del Programa Jefes de Hogar (PJH) y se identificó la región en la que reside el hogar.

Del padre y de la madre se tomaron en cuenta la edad, la condición de actividad económica (ocupado, desocupado e inactivo) y el nivel educativo. La condición de actividad hace posible explorar la evidencia en torno al axioma de la sustitución/complementariedad, explicado antes.

\section{RESUlTADOS}

En el Apartado A se discuten algunos resultados que permiten contextualizar (descriptivamente) el problema de la relación entre pobreza de los hogares y actividades realizadas por NNyA. El Apartado B se ocupa del análisis condicional, mucho más cercano al logro del objetivo principal de este documento: la relación causal entre pobreza de los hogares y actividades realizadas por NNyA.

\section{A. Actividad económica y pobreza de los hogares}

En el Cuadro 1 se ve claramente que tanto la pobreza monetaria, como la Privación de Necesidades Básicas (PNB) (ambas del hogar) marcan claros diferenciales en la participación de los NNyA. 
Jorge A. Paz y Carolina Piselli

Cuadro 1. Tasa de actividad (\%) de NNyA según condición de pobreza del hogar (CPH).

Regiones de Argentina

2004

Tasa de actividad

\begin{tabular}{|c|c|c|c|}
\hline \multirow{2}{*}{$\mathrm{CPH}$} & \\
\hline & Mercado & Doméstica & Autoconsumo \\
\hline
\end{tabular}

Umbral monetario

$\begin{array}{lccc}\text { (BA (Extremo) } & 13,1 & 10,1 & 6,4 \\ \text { CBT (Pobre) } & 10,0 & 9,5 & 5,2 \\ \text { No pobre } & 7,7 & 5,1 & 3,8\end{array}$

Umbral PNB

$\begin{array}{llll}\text { Pobre } & 12,3 & 10,5 & 7,0\end{array}$

$\begin{array}{llll}\text { No pobre } & 9,3 & 5,5 & 3,1\end{array}$

Nota: CBA: canasta básica alimentaria; CBT: canasta básica total; PNB: privación de necesidades materiales básicas, principalmente relacionada con la calidad de la vivienda.

Fuente: Construcción propia con datos de la EanNa, 2004.

La tasa de actividad es sensible a todas las medidas de pobreza monetaria. Se puede apreciar también en el Cuadro 1 que la presencia de al menos una de las privaciones materiales genera una fuerte disparidad de participación. En efecto, el análisis descriptivo realizado sugiere que los hechos se ajustan adecuadamente a lo que cabría esperar por razonamientos de tipo intuitivo y por la HL: la tasa de actividad de los NNyA está inversamente relacionada con el ingreso familiar per cápita.

Como muestran otras investigaciones (por ejemplo Waisgrais, 2007a), las relaciones que surgen del cuadro anterior son diferentes por el género de los NNyA, así como también por sus edades específicas y por las regiones geográficas. Pero antes de examinar estos diferenciales, es necesario aclarar que hay muchos elementos que están relacionados tanto con la condición de pobreza del hogar como con el trabajo de NNyA, provocando una suerte de correlación espuria que debe ser necesariamente tenida en cuenta y que limita seriamente el análisis puramente descriptivo. Estos temas son tratados a continuación en el apartado siguiente. 


\section{B. Análisis condicional}

A pesar de los resultados descriptivos discutidos en el apartado anterior, el análisis condicional que se presenta en este apartado permite afirmar que ni la pobreza monetaria (en sus dos expresiones, СвА у Свт), ni las privaciones materiales ( $\mathrm{PNB})$, son determinantes de peso en la decisión de los hogares de enviar los NNyA a trabajar. La significatividad encontrada para los coeficientes de las regresiones del Cuadro A.2 (Apéndice), no permiten rechazar la hipótesis de ausencia de relación entre estas variables. La conclusión general se mantiene al diferenciar por género y por tipo de tarea desarrollada (cuadros A.2, A.2a y A.2b, Apéndice). Las excepciones a esta regla son pocas: el número de privaciones es significativo para las actividades de autoconsumo y doméstica (Cuadro A.2, Apéndice, columnas 3 y 4). Entre los varones dicha significatividad desaparece (Cuadro A.2a, Apéndice) y entre las mujeres cobra mayor fuerza el autoconsumo (Cuadro A.2b, columna 3). En el Cuadro 2 se resumen los efectos principales para una selección de casos, señalando sólo la significación parcial de cada variable de pobreza, el signo y el nivel de significancia de la prueba.

Cuadro 2. Resumen de algunas relaciones encontradas entre pobreza y actividad de NNYA.

Regiones de Argentina

2004

\begin{tabular}{lcccccc}
\hline \multirow{2}{*}{ Género/tipo de actividad } & \multicolumn{3}{c}{ Varones } & \multicolumn{3}{c}{ Mujeres } \\
\cline { 2 - 7 } & CBA & CBT & PNB & CBA & CBT & PNB \\
\hline General & No & No & No & No & No & No \\
Mercado & No & No & No & No & No & No \\
Autoconsumo & No & No & No & No & No & Si (+) $1 \%$ \\
Doméstica & No & No & No & No & No & No \\
\hline
\end{tabular}

Nota: CBA: canasta básica alimentaria; CBT: canasta básica total; PNB: privación de necesidades básicas. №, significa que no se rechaza la hipótesis de ausencia de relación. Sí, significa que sí se rechaza. A esta última la acompañan el nivel de significación de la prueba y el signo que especifica el tipo de relación hallada.

Fuente: Cuadros A.2a y A.2b (Apéndice).

Sólo 1 de las 24 comparaciones va en línea con la hipótesis de lujo (HL). Dicho de otra manera: las disparidades de actividad económica de nNya que residen en hogares clasificados por niveles de pobreza que se aprecian a nivel descriptivo (Cuadro 1) generados por otros factores ligados quizá a la pobreza, pero 
no por la pobreza entendida como ingresos insuficientes para la superación de umbrales y/o privaciones materiales. Estos resultados van en la dirección de los seis trabajos mencionados en Kambhampati y Rajan (2005) que no logran validar la hipótesis LH; claro que no se ha explorado aquí la hipótesis de relación no lineal entre el ingreso familiar y el trabajo infantil (o entre riqueza y trabajo infantil como en Bhalotra y Heady, 2003 y en Basu et al, 2010), porque el objetivo fue estudiar el impacto de la pobreza (y no de los ingresos) sobre el trabajo de NNyA.

Entre esos factores puede verse que la edad y el género de NNyA, como así también el lugar en el que reside el hogar (región, zona rural/urbana) marcan diferencias pronunciadas. La participación económica sigue con la edad, un perfil de "U-invertida", lo que aparece reflejado en los signos de la variable "edad" (positivo) y "cuadrado de la edad" (negativo). La edad de NNyA es un factor que impacta no sólo por la elevación progresiva del salario que pueden obtener en el mercado, sino también por la restricción que enfrentan las firmas de contratar trabajo de menores. Las edades mínimas varían entre países y hay autores que sostienen que la ratificación de los convenios de la Organización Internacional del Trabajo respecto a dichas edades no tiene un efecto sobre la tasa de actividad de niñas, niños y jóvenes, ni sobre las tasas de asistencia a la escuela (Boockmann, 2010). Pero lo cierto es que superada esta restricción legal, el salario que puede obtener NNyA aumenta con la edad, lo que implica un acicate para una mayor participación económica.

Por su parte, los varones participan más que las mujeres en el mercado y en autoconsumo; y éstas más que aquéllos en actividades domésticas (intensas). La región NEA es la única que registra menores tasas de actividad y en el área rural la actividad es mayor que en la urbana, con excepción de las tareas domésticas que parecen ser independientes de la zona de residencia del hogar. Este resultado que aparece en otros estudios, no resulta trivial. Como se sostiene en una investigación reciente que discute resultados análogos para Bolivia, la mayor responsabilidad en asuntos domésticos asignada a las niñas puede impactar adversamente en su desarrollo educativo y profesional futuro. Si las niñas deben sustraer tiempo del dedicado al estudio para trabajar en el hogar, pueden ver afectados su continuidad y rendimiento en la escuela, generando diferencias de género en los resultados que luego ellas obtienen en el mercado de trabajo (Zapata et al, 2010).

Las características de madres y padres es muy importante para definir la participación de NNYA en el mercado laboral. La mayor educación de madres y de padres disminuye la probabilidad de que nNyA realicen algún tipo de actividad económica. Si bien es un resultado conocido en la literatura que la educación del 
padre impacta más en la educación (y el trabajo) de los hijos varones, mientras que la educación de la madre ejerce un impacto mayor en la educación (y el trabajo) de las hijas mujeres (Whaba, 2005), puede verse que en la Argentina es la educación de la madre la que impacta mayormente tanto en nińas, como en niños y adolescentes de ambos sexos (Cuadros A.2a y A.2b, Apéndice). Este efecto se verifica para las tres actividades (mercado, autoconsumo y hogar), pero es importante notar que la educación de la madre reduce más el trabajo doméstico de niños y adolescentes varones que el de niñas y adolescentes mujeres (Cuadros A.2a y A.2b, Apéndice). Esta conclusión sugiere que aun en aquellos ambientes educados se verifica un importante sesgo de género que afecta más a las niñas que a los niños.

¿La actividad económica de NNyA es sustituta o complementaria de la de sus padres (padre y madre)? El estatus ocupacional de los padres ha sido tratado en la literatura en términos de los efectos que provoca el desempleo del jefe de hogar sobre la probabilidad de los niños y jóvenes de abandonar la educación (Skoufias y Parker, 2006). Si bien ésta ha sido la tendencia, interesa aquí tratar más bien el efecto estructural, de largo plazo de la condición de actividad de los padres sobre la probabilidad de NNyA de desarrollar alguna actividad económica. Para hacer esto se introdujeron en el análisis condicional las variables "madre/padre ocupada/o" y "madre/padre desocupada/o".

Los resultados obtenidos sugieren que los hijos de madres trabajadoras tienen una probabilidad más elevada de trabajar en el mercado y en el hogar, que los hijos de madres inactivas (categoría de referencia). El efecto sobre el trabajo para el mercado podría deberse al acompañamiento de NNyA en actividades callejeras o similares, ante la imposibilidad de las mujeres de dejar a sus hijos/hijas al cuidado de especialistas (jardines maternales, por ejemplo). Esto es lo que encuentra Ray (2000) para Pakistán quien remarca que en esos casos de acompañamiento, resulta altamente probable que el niño se inicie en el trabajo. En el mismo sentido se ha observado que la oferta laboral de algunas actividades rurales está sujeta a restricciones de acompañamiento de menores (González Román, 2006); esto quiere decir que los padres están dispuestos a vender su fuerza laboral sólo si el empleador permite que vayan acompañados por sus hijos, dado que no tienen dónde dejarlos. El efecto sobre el trabajo doméstico, podría deberse a que los NNyA, y especialmente las niñas, realicen el trabajo de sus madres (que ahora trabajan) o que colaboren en las tareas que sus madres realizan en sus casas pero con un fin comercial (Willoughby, 1890).

La presencia de niños entre 0 y 4 años de edad en el hogar (quizás hermanos) aumenta la probabilidad de NNyA de trabajar para el mercado y de realizar tareas domésticas intensas. Además, el efecto es más fuerte y nítido en niñas y 
adolescentes mujeres, dejando muy clara la dimensión de género en la división del trabajo hogareño de NNyA. Todavía más: los hermanos acrecientan la probabilidad de niños y adolescentes varones de trabajar para el mercado (Cuadro A.2a, Apéndice), y la de niñas y adolescentes mujeres de trabajar en todo tipo de tareas (Cuadro A.2b, Apéndice). ${ }^{8} \mathrm{Al}$ respecto conviene destacar alguna evidencia reciente de disparidades de participación económica femenina de mujeres casadas según el género de los hijos (Casal y Paz Terán, 2010). Al parecer, la presencia de hijos varones promueve el retiro del mercado de trabajo de la madre. Extrapolando este resultado, podría decirse que las niñas y adolescentes mujeres que trabajan en sus casas lo hacen reemplazando el trabajo materno; mientras que aquellas otras, hermanas de varones pequeños que trabajan para el mercado, estarían sustituyendo a la madre que se retira de dichas actividades.

La asistencia disminuye el trabajo infantil y adolescente en casi todas las especificaciones y para ambos sexos. Pero ocurre también que los que asisten a un establecimiento público registran una mayor probabilidad de trabajar para el mercado, comparados con NNyA que asisten a establecimientos no públicos. En esto puede tener que ver la disponibilidad de escolaridad extendida: entre los establecimientos no públicos es más común la jornada doble, lo que reduce el tiempo de NNyA disponible para el trabajo.

Un último factor incorporado en las regresiones es la recepción de un programa de ayuda social; más específicamente la consideración de si en el hogar hay algún perceptor del PJH, implementado en la Argentina en el año 2002. Puede verse que el programa de transferencia de ingresos tiene un efecto dual: por un lado, reduce la probabilidad de que los varones (nińos y adolescentes) realicen tareas domésticas y de autoconsumo, y aumenta la probabilidad de que las mujeres (niñas y adolescentes) trabajen para el mercado. Dado que estos programas tienen como objetivo promover la asistencia a la escuela, los resultados observados para los varones son lógicos y naturales (los hogares pJH utilizan menos tiempo en trabajar y más en estudiar). Sin embargo sorprende el resultado para las mujeres. La hipótesis plausible sobre este efecto sería la siguiente: madres adolescentes que declaran tener a cargo menores y que se activan, ofreciendo su fuerza laboral, a cambio del beneficio que aporta el programa. Un análisis detallado de este efecto escapa al objetivo central de este estudio, pero requeriría un análisis más profundo de las edades en las que el efecto es importante.

8 Es altamente probable que las tareas que realizan esas nińas y adolescentes mujeres tanto en el mercado como en el hogar, sean las mismas y que estén relacionadas con el cuidado y con la reproducción en términos más generales. Este efecto es observado también para el caso boliviano por Zapata et al (2010). 
El Cuadro 3 ofrece una extensión de los resultados discutidos en los párrafos precedentes. Se resume en él lo encontrado luego de estimar regresiones similares a las que aparecen en los cuadros A.2, A.2a y A.2b (todas del Apéndice) pero segmentando en grupo las edades: 5 a 13 por un lado y 14 a 17 por otro, y conservando la división por género. ${ }^{9}$

Las comparaciones posibles se elevan ahora a 48, de las cuales en sólo 7 se rechaza la hipótesis de ausencia de relación entre trabajo de nNyA y pobreza de los hogares. En términos generales puede decirse que los 7 rechazos se agrupan en el tramo de menor edad: 5-13, y mayoritariamente en niñas (5 de los 7). Es decir que la sensibilidad del trabajo de NNyA a la pobreza de los hogares se verificaría en algunos entornos, pero sólo entre niñas y niños (no entre los adolescentes) y más en niñas que en niños. Además puede verse que las privaciones materiales (más que la pobreza monetaria) impactan más fuertemente ( 5 de los 7 rechazos se dan con la variable PNB).

\section{Cuadro 3}

Resumen de algunas relaciones encontradas entre pobreza y actividades de NNYA según el género y la edad.

Regiones de Argentina

2004

\begin{tabular}{|c|c|c|c|c|c|c|}
\hline \multirow{2}{*}{ Género/tipo de actividad } & \multicolumn{3}{|c|}{$5-73$} & \multicolumn{3}{|c|}{ 14-17 } \\
\hline & $C B A$ & $C B T$ & $P N B$ & $C B A$ & $C B T$ & $P N B$ \\
\hline \multicolumn{7}{|l|}{ Varones } \\
\hline General & No & No & $\mathrm{Si}(+) 5 \%$ & No & No & No \\
\hline Mercado & № & No & Si (+) $10 \%$ & No & No & No \\
\hline Autoconsumo & № & No & No & No & No & No \\
\hline Doméstica & No & No & No & No & No & No \\
\hline \multicolumn{7}{|l|}{ Mujeres } \\
\hline General & $\mathrm{Si}(+) 10 \%$ & No & $\mathrm{Si}(+) 10 \%$ & No & No & No \\
\hline Mercado & Si (+) 10\% & No & No & No & No & No \\
\hline Autoconsumo & № & No & $\mathrm{Si}(+) 5 \%$ & No & No & № \\
\hline Doméstica & No & No & $\mathrm{Si}(+) 5 \%$ & No & No & № \\
\hline
\end{tabular}

Nota: CBA: canasta básica alimentaria; CBT: canasta básica total; PNB: privación de necesidades básicas (ver texto para detalles). №, significa que no se rechaza la hipótesis de ausencia de relación. Sí, significa que sí se rechaza. A esta última le acompañan el nivel de significación de la prueba y el signo que especifica el tipo de relación hallada.

Fuente: Construcción propia con datos de la EanNA.

$9 \quad$ Esas regresiones no se incluyen por razón de espacio. No obstante, están disponibles para quien las requiera. Los e-mails de los autores figuran al principio del documento. 
Lo anterior lleva a reflexionar sobre las características que asume el altruismo paterno en la Argentina. Al parecer por los datos disponibles, el trabajo adolescente no estaría condicionado por la pobreza de los hogares, mientras que el trabajo de niñas y niños se muestra sensible a la pobreza por privaciones materiales y más el de niñas que el de niños. Los padres si bien altruistas, se muestran más altruistas con algunos hijos que con otros. En principio, habría cierta discriminación por género en la asignación de tareas dentro del hogar, y dicha discriminación estaría operando en contra de las niñas fundamentalmente.

\section{CONCLUSIONES}

La principal conclusión de este estudio es que, a pesar de la relación que a nivel descriptivo puede hallarse, ni la pobreza monetaria ni las privaciones materiales, son determinantes cruciales y de peso en la decisión de los hogares de hacer trabajar a NNyA. Esta conclusión (que va en línea con un conjunto importante de estudios sobre el tema) invita a repensar las políticas públicas orientadas a la reducción y/o erradicación del trabajo infantil y juvenil que ponen el acento en el combate a la pobreza. Los hogares de las regiones argentinas examinadas aquí, no se comportan como los padres altruistas del modelo de Basu y Van (1998), o las determinaciones que ellos toman acerca de actividades económicas de NNyA estarían radicando más en la estructura de preferencias de los hogares (educación de madre y padre, básicamente), y menos en restricciones objetivas tales como insuficiencia de ingresos o de activos de otro tipo (en línea con del Río y Cumsille, 2008).

Asoman también en el análisis evidencias sobre restricciones fácticas (escuelas públicas con jornada simple, o con escasez de ofertas extracurriculares) que tienen que ver con aspectos institucionales o sutilmente económicos y que pueden ser muy eficaces en la lucha contra el trabajo infantil y adolescente. La evidencia es muy clara en estos temas. Se aprecia una alta tasa de matriculación (NNyA van mayoritariamente a la escuela), a pesar de lo cual trabajan (tanto para el mercado, para el autoconsumo o para el hogar), en el tiempo que les queda disponible luego de la asistencia a clases. ${ }^{10} \mathrm{~A}$ pesar de esto, buena parte de la

10 La matriculación no implica asistencia a la escuela. Puede ocurrir que NNyA asistan esporádicamente o que terminen abandonando la escuela para trabajar debido a la falta de recursos en el hogar. Agradecemos especialmente a uno de los árbitros anónimos el haber reparado en este aspecto. 
evidencia se expresa a favor de una puja entre escuela y trabajo y no de sacrificio de ocio entre nnya que trabajan (Paz y Piselli, 2010).

El que el hogar resida en áreas rurales parece ser un factor de importancia en la probabilidad de NNyA de participar como trabajadores. Se observa aquí, como en otras dimensiones del trabajo infantil y adolescente, una clara división por género. En el área rural existe una probabilidad mayor de que un niño y adolescente varón participen en el mercado de trabajo y en actividades de autoconsumo; mientras que en esas áreas, la probabilidad de las niñas y adolescentes mujeres no se ve afectada excepto en las actividades de autoconsumo. Esto es particularmente delicado en el momento de diseñar políticas públicas dado que en estas áreas convergen otros factores que traccionan en contra de la educación y la formación de capital humano de los más pequeños.

También la presencia de menores de 5 años en el hogar, independientemente del género, es un factor importante. Los hermanos de menor edad requieren la atención de NNyA. Esto puede deberse a la escasez de opciones tales como jardines maternales o de ingresos que no permiten la contratación de personal profesional del cuidado. El tema requiere reflexión ya que tienen un sesgo de género muy importante. Siempre la sobrecarga de trabajo en estos casos pesa más sobre las niñas y adolescentes mujeres. Además se detectó diferencias de género en el receptor del cuidado. Cuando el menor de 5 años es un varón existe una probabilidad más alta que la tarea de cuidado la realice la madre, lo que impacta negativamente en la probabilidad de participación en el mercado laboral y, por ende, en una probabilidad mayor de que otros miembros del hogar complementen ingresos.

$\mathrm{Al}$ abrir el análisis por grupo de edad se encontró que si bien el trabajo adolescente no cambia por el estatus de pobreza del hogar, el trabajo infantil sí lo hace, registrando una sensibilidad mayor entre niñas y ante pobreza por privaciones más que la monetaria. En este análisis más detallado se desprenden las preferencias del hogar por el género y la edad de NNyA y una clara desventaja de las niñas ante sus pares masculinos.

Estas conclusiones respaldan un cuerpo importante de literatura que sostiene que el acceso a las escuelas, su calidad, el bajo costo, la disponibilidad de materiales y de una adecuada relación entre los docentes y los alumnos, tendrían un gran impacto en la incidencia del trabajo infantil. Esto ocurre principalmente por la percepción que los padres tienen del valor de la educación como mecanismo de generación de mayores ingresos futuros y no por la escasez actual de ingresos: cuanto mayor sea la calidad de la educación se producirá una mayor acumulación de capital humano y retornos futuros a la educación en igual tiempo de estudio, lo que vuelve más atractiva la escuela frente al trabajo infantil (Bhalotra y Tzannatos, 2003; Cigno et al, 2002; entre otros). 
Hay muchas tareas más por realizar para ampliar y perfeccionar los resultados discutidos a lo largo del presente documento. Entre tales tareas se destacan: a) utilizar otras posibilidades que ofrece la EANNA, como por ejemplo, el periodo de referencia para indagar las actividades de NNyA; $b$ ) incorporar datos de la EANNA que se realizó en la provincia de Córdoba (Argentina) más recientemente (año 2006) y analizar la robustez de los hallazgos de esta versión; $c$ ) imputar ingresos a los hogares con entradas monetarias desconocidas (que son alrededor del $20 \%$ de la muestra total de hogares) y replicar el ejercicio; $d$ ) incorporar alguna medida de pobreza multidimensional; $e$ ) explorar el efecto de otras medidas de pobreza, como por ejemplo de intensidad de la pobreza; $f$ ) estudiar con más detalle la no linealidad de la relación entre ingresos/riqueza y trabajo infantil (con especial referencia a la hipótesis de la "U" invertida).

\section{BIBLIOGRAFÍA}

Basu, Kaushik y Pham Van, "The Economics of Child Labor", en American Economic Review, vol. 88, No 3, USA, AEA, June 1998, pp. 412-427.

Basu, Kaushik y Zafiris Tzannatos, "Child Labor and Development: An Introduction", en World Bank Economic Review, vol. 17, No 2, UsA, The World Bank, December 2003, pp. 145-146.

Basu, Kaushik, Sanghamitra Das, y Bhaskar Dutta, "Child Labor and Household Wealth: Theory and Empirical Evidence of an Inverted-U”, en Journal of Development Economics, vol. 91, No 1, UK, Elsevier B. V., 2010, pp. 8-14.

Bhalotra, Sonia and Christopher Heady, Child Farm Labor: The Wealth Paradox, Discussion Paper, No 03/553, uK, Department of Economics, University of Bristol, August 2003, pp. 1-54.

Bhalotra, Sonia y Zafiris Tzannatos, Child Labor: What Have We Learnt?, en Social Protection Discussion Paper Series, No 0317, usA, The World Bank, September 2003, pp. 1-76.

Boockmann, Bernhard, "The Effect of ILo Minimun Age Conventions on Child Labor and School Attendence: Evidence from Agregate and Individual-Lavel Data", World Development vol. 38 No 5, us, Elsevier, 2010, pp. 679-692.

Brown, Drusilla, "El trabajo infantil en la América Latina. Teoría y evidencia", en López Calva, Luis (coord.), Trabajo infantil. Teoría y lecciones de la América Latina, México, Lecturas 97, Fondo de Cultura Económica, 2006, pp. 93-117. Casal, María y Corina Paz Terán, Women Labor Force Participation and Fertility. The Case of Argentina: 1970-2001, ponencia presentada en la XLv Reunión 
Anual de la Asociación Argentina de Economía Política, Buenos Aires, Argentina, noviembre de 2010.

Cigno, Alessandro, Furio C. Rosati, Zafiris Tzannatos, Child Labor Handbook, in Social Protection Discussion Paper Series, núm. 03-17, usA, The World Bank, May 2002, pp. 1-93.

Del Río, Francisca y Patricio Cumsille, “¿Necesidad económica o preferencias culturales? La justificación parental del trabajo infantil en Chile”, en Psykhe, vol. 17, No 2, República de Chile, 2010, pp. 41-52.

Edmonds, Eric, "Does Child Labor Decline with Improving Economic Status?", en The Journal of Human Resources, vol. 40, No 1, USA, University of Wisconsin, 2005, pp. 7-99.

González Román, Fabiola, El trabajo infantil en el cultivo de café en Nayarit, ponencia presentada en $\mathrm{V}$ Congreso Nacional de AMET, Trabajo y Reestructuración: los Retos del Nuevo Siglo, Centro Multidisciplinario de Investigación Científica, Universidad Autónoma de Nayarit, México, 2006 (consultado el 3 de noviembre de 2010), disponible en: <http://www.izt. uam.mx>.

Kambhampati, Uma y Raji Rajan, "Does Child Work Decrease with Parental Income? The Luxury Axiom Revisited in India", en The European Journal of Development Research, vol. 17, No 4, uK, Routledges, Taylor \& Francis Group, December 2005, pp. 649-680.

Ministerio de Educación, Ley de Educación Nacional (LEN), N²6.206, Ministerio de Educación, Presidencia de la Nación, Buenos Aires, Argentina. Ministerio de Trabajo, Empleo y Seguridad Social, Oficina Internacional del Trabajo (мтEss/OIт), Documento preliminar para la elaboración de una definición y de tipologías de trabajo infantil y adolescente con los datos de la EANNA, documento interno no publicado, Buenos Aires, Argentina, 2005.

International Labour Office, Report VI (1) Child Labor: Targeting the Intolerable Sixth item on the Agenda, International Labour Office (ILO), Geneva, 1998.

Paz, Jorge y Carolina Piselli, Infancia y adolescencia, educación y trabajo en América Latina y El Caribe, ponencia presentada en Iv Congreso de la Asociación Latinoamericana de Población, La Habana, Cuba, noviembre de 2010.

Ray, Ranjan, "Analysis of Child Labour in Peru and Pakistan: A Comparative Study", en Journal of Population Economics, vol. 13, No 1, Germany, IZA, 2000, pp. 3-19.

Sauma, Pablo, Trabajo infantil: causa y efecto de la perpetuación de la pobreza. Programa Internacional para la Erradicación del Trabajo Infantil (IPEC) de la Oficina Internacional del Trabajo (оіт), San José, огт/IPEC, 2007. 
Skoufias, E. y S. Parker, "Job Loss and the Family Adjustment in Work and Schooling During the Mexican Peso Crisis", Journal of Labor Economics, vol. 19, No 1, Chicago, Illininos, USA, 2006, pp. 163-181.

Schluter, Christian y Jackeline Whaba, "Are Parents Altruistic? Evidence from Mexico", en Journal of Population Economics, vol. 23, No 3, Germany, IZA, 2008, pp. 933-1433.

Torre, Juan, "Determinantes del trabajo infantil en Argentina”, Anales, Asociación Argentina de Economía Política, XLIII Reunión Anual, Buenos Aires, Argentina, noviembre de 2008 (consultado el 8 de octubre de 2009), disponible en: <www.aaep.org.ar/anales>.

Waisgrais, Sebastián, "El trabajo de niñas, niños y adolescentes. Concepto, metodología y resultados", en Organización Internacional del Trabajo (coord.), El trabajo infantil en la Argentina. Análisis y desafíos para la política pública, Oficina Internacional del Trabajo y Ministerio de Trabajo, Empleo y Seguridad Social, Argentina, 2007a, pp. 99-128.

Waisgrais, Sebastián, "Aspectos socioeconómicos vinculados a la relación entre trabajo infantil y educación”, en Organización Internacional del Trabajo (coord.), El trabajo infantil en la Argentina. Análisis y desafíos para la política pública, Oficina Internacional del Trabajo y Ministerio de Trabajo, Empleo y Seguridad Social, Argentina, 2007b, pp. 167-203.

Willoughby, Westel, "Child Labor", American Economic Association, 1890, U.s., vol. 5 No 5, pp. 5-70.

Zapata, D., D. Contreras y S. Dercon, "Child Labor and Schooling in Bolivia: Who's Falling Behind? The Roles of Domestic Work, Gender, and Ethnicity", World Development, doi:10.1016/j.worlddev.2010.08.022, USA, 2010. 


\section{APÉNDICE}

Cuadro A. 1. Información de la muestra y estadísticos descriptivos básicos

\begin{tabular}{|c|c|c|c|c|}
\hline Variables & Tipo & Media & Máximo & Mínimo \\
\hline \multicolumn{5}{|l|}{ Dependientes } \\
\hline Tasa de actividad general & Dummy & 0,234 & 0 & 1 \\
\hline Tasa de actividad mercado & Dummy & 0,101 & 0 & 1 \\
\hline Tasa de actividad autoconsumo & Dummy & 0,051 & 0 & 1 \\
\hline Tasa de actividad doméstica & Dummy & 0,082 & 0 & 1 \\
\hline \multicolumn{5}{|l|}{ Independientes principales } \\
\hline Hogar en pobreza extrema (CBA) & Dummy & 0,293 & 0 & 1 \\
\hline Hogar en pobreza (CBT) & Dummy & 0,360 & 0 & 1 \\
\hline Hogar pobre por PNB & Dummy & 0,472 & 0 & 1 \\
\hline Número de privaciones & Intervalo & 0,833 & 0 & 6 \\
\hline \multicolumn{5}{|l|}{ Controles } \\
\hline Edad & Dummy & 10,923 & 5 & 17 \\
\hline Varón & Dummy & 0,521 & 0 & 1 \\
\hline Región NEA & Dummy & 0,108 & 0 & 1 \\
\hline Región NOA & Dummy & 0,219 & 0 & 1 \\
\hline Mendoza & Dummy & 0,084 & 0 & 1 \\
\hline Área rural & Dummy & 0,064 & 0 & 1 \\
\hline Edad padre & Intervalo & 34,255 & & \\
\hline Edad madre & Intervalo & 37,178 & & \\
\hline Educación padre (años) & Intervalo & 6,788 & 0 & 17 \\
\hline Educación madre (años) & Intervalo & 8,609 & 0 & 17 \\
\hline Padre ocupado & Dummy & 0,720 & 0 & 1 \\
\hline Padre desocupado & Dummy & 0,043 & 0 & 1 \\
\hline Madre ocupada & Dummy & 0,471 & 0 & 1 \\
\hline Madre desocupada & Dummy & 0,085 & 0 & 1 \\
\hline Niños entre 0 y 4 años varones & Intervalo & 0,268 & & \\
\hline Niños entre 0 y 4 años mujeres & Intervalo & 0,253 & & \\
\hline Asiste a la escuela & Dummy & 0,939 & 0 & 1 \\
\hline Establecimiento público & Dummy & 0,718 & 0 & 1 \\
\hline Hogar beneficiario con PJH & Dummy & 0,138 & 0 & 1 \\
\hline
\end{tabular}

Nota: CBA: canasta básica alimentaria; CBT: canasta básica total; PNB: privaciones de necesidades básicas; NEA: Nordeste Argentino; NOA: Noroeste Argentino; PJH: Programa Jefes de Hogar.

Fuente: Construcción propia, principalmente con datos de EanNA. 
Jorge A. Paz y Carolina Piselli

Cuadro A.2. Determinantes de la actividad económica de NNYA

\begin{tabular}{|c|c|c|c|c|}
\hline \multirow{3}{*}{ Variables independientes } & \multirow{2}{*}{ Trabaja } & \multicolumn{3}{|c|}{ MNL (coeficientes) } \\
\hline & & Mercado & Autoconsumo & Doméstica \\
\hline & (1) & (2) & (3) & (4) \\
\hline Hogar con pobreza extrema & $\begin{array}{c}0,127 \\
(0,135)\end{array}$ & $\begin{array}{c}0,080 \\
(0,185)\end{array}$ & $\begin{array}{c}0,111 \\
(0,233)\end{array}$ & $\begin{array}{c}0,223 \\
(0,210)\end{array}$ \\
\hline Hogar pobre & $\begin{array}{l}0,065 \\
(0,119)\end{array}$ & $\begin{array}{l}-0,031 \\
(0,173)\end{array}$ & $\begin{array}{c}0,005 \\
0,005 \\
(0,199)\end{array}$ & $\begin{array}{c}0,204 \\
(0,192)\end{array}$ \\
\hline Número de privaciones & $\begin{array}{l}0,095^{\star} \\
(0,049)\end{array}$ & $\begin{array}{c}0,011 \\
(0,067)\end{array}$ & $\begin{array}{c}0,142^{\star \star} \\
(0,069)\end{array}$ & $\begin{array}{l}0,146^{\star} \\
(0,075)\end{array}$ \\
\hline Edad & $\begin{array}{c}0,454^{* * *} \\
(0,099)\end{array}$ & $\begin{array}{c}0,736^{* * *} \\
(0,139)\end{array}$ & $\begin{array}{c}0,180 \\
(0,167)\end{array}$ & $\begin{array}{c}0,537^{\star * \star} \\
(0,153)\end{array}$ \\
\hline Cuadrado de la edad & $\begin{array}{c}-0,009 * \star \\
(0,004)\end{array}$ & $\begin{array}{c}-0,017^{\star \star \star} \\
(0,006)\end{array}$ & $\begin{array}{l}-0,001 \\
(0,007)\end{array}$ & $\begin{array}{c}-0,013^{\star \star} \\
(0,006)\end{array}$ \\
\hline Varón & $\begin{array}{l}-0,004 \\
(0,085)\end{array}$ & $\begin{array}{c}0,368^{\star \star \star} \\
(0,119)\end{array}$ & $\begin{array}{c}0,831^{\star \star *} \\
(0,167)\end{array}$ & $\begin{array}{c}-1,000^{\star \star *} \\
(0,148)\end{array}$ \\
\hline Reside en el NEA & $\begin{array}{c}-0,325^{\star \star *} \\
(0,098)\end{array}$ & $\begin{array}{c}-0,329^{\star \star} \\
(0,137)\end{array}$ & $\begin{array}{c}-0,443^{\star \star} \\
(0,174)\end{array}$ & $\begin{array}{c}-0,268^{\star} \\
(0,145)\end{array}$ \\
\hline Reside en el NOA & $\begin{array}{l}-0,051 \\
(0,090)\end{array}$ & $\begin{array}{l}-0,123 \\
(0,121)\end{array}$ & $\begin{array}{l}-0,231 \\
(0,163)\end{array}$ & $\begin{array}{c}0,102 \\
(0,136)\end{array}$ \\
\hline Reside en Mendoza & $\begin{array}{l}-0,030 \\
(0,114)\end{array}$ & $\begin{array}{c}0,237 \\
(0,148)\end{array}$ & $\begin{array}{l}-0,243 \\
(0,221)\end{array}$ & $\begin{array}{c}-0,371^{*} \\
(0,198)\end{array}$ \\
\hline Reside en área rural & $\begin{array}{l}0,281^{\star \star} \\
(0,112)\end{array}$ & $\begin{array}{l}0,274^{\star} \\
(0,146)\end{array}$ & $\begin{array}{c}0,918^{\star \star \star} \\
(0,169)\end{array}$ & $\begin{array}{l}-0,256 \\
(0,186)\end{array}$ \\
\hline Edad del padre & $\begin{array}{c}0,003 \\
(0,003)\end{array}$ & $\begin{array}{l}-0,006 \\
(0,004)\end{array}$ & $\begin{array}{c}0,018^{\star \star \star} \\
(0,005)\end{array}$ & $\begin{array}{c}0,002 \\
(0,005)\end{array}$ \\
\hline Edad de la madre & $\begin{array}{c}-0,006^{\star} \\
(0,003)\end{array}$ & $\begin{array}{c}0,003 \\
(0,005)\end{array}$ & $\begin{array}{c}-0,009^{\star} \\
(0,005)\end{array}$ & $\begin{array}{c}-0,015^{\star \star \star} \\
(0,005)\end{array}$ \\
\hline Educación del padre & $\begin{array}{c}-0,031^{* *} \\
(0,015)\end{array}$ & $\begin{array}{l}-0,020 \\
(0,019)\end{array}$ & $\begin{array}{l}-0,042 \\
(0,031)\end{array}$ & $\begin{array}{c}-0,038^{\star} \\
(0,022)\end{array}$ \\
\hline Educación de la madre & $\begin{array}{c}-0,054^{\star \star \star} \\
(0,013)\end{array}$ & $\begin{array}{c}-0,068^{\star \star \star} \\
(0,017)\end{array}$ & $\begin{array}{l}-0,025 \\
(0,021)\end{array}$ & $\begin{array}{c}-0,057^{\star \star \star} \\
(0,019)\end{array}$ \\
\hline Padre ocupado & $\begin{array}{l}-0,054 \\
(0,141)\end{array}$ & $\begin{array}{c}0,154 \\
(0,210)\end{array}$ & $\begin{array}{r}-0,245 \\
(0,203)\end{array}$ & $\begin{array}{c}0,012 \\
(0,223)\end{array}$ \\
\hline Padre desocupado & $\begin{array}{l}-0,329 \\
(0,246)\end{array}$ & $\begin{array}{l}-0,117 \\
(0,344)\end{array}$ & $\begin{array}{r}-0,553 \\
(0,386)\end{array}$ & $\begin{array}{l}-0,249 \\
(0,384)\end{array}$ \\
\hline Madre ocupada & $\begin{array}{c}0,439 * \star \star \\
(0,095)\end{array}$ & $\begin{array}{c}0,487^{\star \star \star} \\
(0,141)\end{array}$ & $\begin{array}{c}0,371^{\star *} \\
(0,157)\end{array}$ & $\begin{array}{c}0,461^{\star * \star} \\
(0,135)\end{array}$ \\
\hline Madre desocupada & $\begin{array}{c}0,082 \\
(0,179)\end{array}$ & $\begin{array}{c}0,171 \\
(0,253)\end{array}$ & $\begin{array}{c}0,587^{\star \star} \\
(0,287)\end{array}$ & $\begin{array}{c}-0,524^{\star} \\
(0,292)\end{array}$ \\
\hline Menores de 5 años, varones & $\begin{array}{c}0,258^{\star \star \star} \\
(0,071)\end{array}$ & $\begin{array}{c}0,335^{\star \star \star} \\
(0,100)\end{array}$ & $\begin{array}{c}0,103 \\
(0,124)\end{array}$ & $\begin{array}{c}0,250^{\star \star \star} \\
(0,097)\end{array}$ \\
\hline Menores de 5 años, mujeres & $\begin{array}{c}0,367^{\star \star \star} \\
(0,080)\end{array}$ & $\begin{array}{c}0,350 * \star \star \\
(0,121)\end{array}$ & $\begin{array}{c}0,173 \\
(0,159)\end{array}$ & $\begin{array}{c}0,486^{\star \star \star} \\
(0,100)\end{array}$ \\
\hline Asiste a la escuela & $\begin{array}{c}-1,033^{\star \star \star} \\
(0,204)\end{array}$ & $\begin{array}{c}-1,338 * \star \star \\
(0,274)\end{array}$ & $\begin{array}{c}-0,908^{\star \star} \\
(0,385)\end{array}$ & $\begin{array}{c}-0,684^{\star *} \\
(0,298)\end{array}$ \\
\hline Escuela pública & $\begin{array}{c}0,704^{* * *} \\
(0,151)\end{array}$ & $\begin{array}{c}0,853^{* * *} \\
(0,226)\end{array}$ & $\begin{array}{c}0,826^{\star \star *} \\
(0,293)\end{array}$ & $\begin{array}{l}0,454^{\star \star} \\
(0,222)\end{array}$ \\
\hline Programa Jefes de Hogar & $\begin{array}{l}-0,178 \\
(0,119)\end{array}$ & $\begin{array}{c}0,115 \\
(0,165)\end{array}$ & $\begin{array}{c}-0,413^{\star \star} \\
(0,201)\end{array}$ & $\begin{array}{c}-0,410^{\star \star} \\
(0,167)\end{array}$ \\
\hline Ordenada & $\begin{array}{c}-4,430^{\star \star \star} \\
(0,574)\end{array}$ & $\begin{array}{c}-7,631^{\star \star \star} \\
(0,871)\end{array}$ & $\begin{array}{c}-4,929 \star \star \star \\
(0,954)\end{array}$ & $\begin{array}{c}-5,220^{\star \star \star} \\
(0,879) \\
\end{array}$ \\
\hline Observaciones & 9549 & 9459 & & \\
\hline Pseudo-R2 & 0,162 & 0,150 & & \\
\hline
\end{tabular}

Nota: Error estándar entre paréntesis. ${ }^{\star \star \star} 1 \%,{ }^{\star \star} 5 \%,{ }^{\star} 1 \%$.

Fuente: Construcción propia con datos EANNA. 
Cuadro A.2a. Determinantes de la actividad económica de niños y adolescentes varones

\begin{tabular}{|c|c|c|c|c|}
\hline \multirow{3}{*}{ Variables independientes } & \multirow[b]{2}{*}{ Trabaja } & \multicolumn{3}{|c|}{ MNL (coeficientes) } \\
\hline & & Mercado & Autoconsumo & Doméstica \\
\hline & (1) & $(2)$ & (3) & (4) \\
\hline Hogar con pobreza extrema & 0,039 & $-0,063$ & $\begin{array}{l}-0,045 \\
-0,2801\end{array}$ & 0,398 \\
\hline & $(0,186)$ & $(0,241)$ & $(0,280)$ & $\begin{array}{c}(0,393) \\
0471\end{array}$ \\
\hline Hogar pobre & $\begin{array}{l}0,018 \\
(0,169)\end{array}$ & $\begin{array}{l}-0,111 \\
(0,228)\end{array}$ & $\begin{array}{l}-0,088 \\
(0,238)\end{array}$ & $\begin{array}{l}0,421 \\
(0,385)\end{array}$ \\
\hline Número de privaciones & $\begin{array}{c}0,105 \\
(0,067)\end{array}$ & $\begin{array}{c}0,113 \\
(0,086)\end{array}$ & $\begin{array}{c}0,060 \\
(0,082)\end{array}$ & $\begin{array}{c}0,141 \\
(0,140)\end{array}$ \\
\hline Edad del niño & $\begin{array}{c}0,590^{* \star \star} \\
(0,130)\end{array}$ & $\begin{array}{c}0,794^{\star * \star} \\
(0,180)\end{array}$ & $\begin{array}{l}0,321 \\
(0,195)\end{array}$ & $0,867^{\star * *}$ \\
\hline Cuadrado de la edad del niño & $\begin{array}{c}-0,015^{\star \star \star} \\
(0,005)\end{array}$ & $\begin{array}{c}-0,020^{\star \star \star} \\
(0,007)\end{array}$ & $\begin{array}{l}-0,005 \\
(0,008)\end{array}$ & $\begin{array}{c}-0,031^{* \star *} \\
(0,012)\end{array}$ \\
\hline Reside en el NEA & $\begin{array}{c}-0,364^{\star \star \star} \\
(0,138)\end{array}$ & $\begin{array}{l}-0,251 \\
(0,182)\end{array}$ & $\begin{array}{c}-0,482^{\star \star} \\
(0,207)\end{array}$ & $\begin{array}{c}-0,487^{\star} \\
(0,274)\end{array}$ \\
\hline Reside en el NOA & $\begin{array}{l}-0,203 \\
(0,124)\end{array}$ & $\begin{array}{l}-0,203 \\
(0,161)\end{array}$ & $\begin{array}{c}-0,366^{*} \\
(0,199)\end{array}$ & $\begin{array}{l}-0,013 \\
(0,235)\end{array}$ \\
\hline Reside en Mendoza & $\begin{array}{r}-0,063 \\
(0,158)\end{array}$ & $\begin{array}{c}0,228 \\
(0,194)\end{array}$ & $\begin{array}{l}-0,367 \\
(0,267)\end{array}$ & $\begin{array}{l}-0,601 \\
(0,395)\end{array}$ \\
\hline Reside en área rural & $\begin{array}{c}0,329 * \star \\
(0,146)\end{array}$ & $\begin{array}{c}0,291 \\
(0,180)\end{array}$ & $\begin{array}{c}0,866^{\star * *} \\
(0,214)\end{array}$ & $\begin{array}{c}-0,607^{\star} \\
(0,357)\end{array}$ \\
\hline Edad del padre & $\begin{array}{c}0,002 \\
(0,004)\end{array}$ & $\begin{array}{l}-0,008 \\
(0,005)\end{array}$ & $\begin{array}{c}0,017^{\star \star \star} \\
(0,006)\end{array}$ & $\begin{array}{l}-0,002 \\
(0,010)\end{array}$ \\
\hline Edad de la madre & $\begin{array}{l}-0,004 \\
(0,005)\end{array}$ & $\begin{array}{c}0,001 \\
(0,006)\end{array}$ & $\begin{array}{l}-0,010 \\
(0,007)\end{array}$ & $\begin{array}{l}-0,007 \\
(0,009)\end{array}$ \\
\hline Educación del padre & $\begin{array}{c}-0,037^{\star} \\
(0,020)\end{array}$ & $\begin{array}{l}-0,028 \\
(0,026)\end{array}$ & $\begin{array}{c}-0,067^{\star} \\
(0,035)\end{array}$ & $\begin{array}{l}-0,014 \\
(0,037)\end{array}$ \\
\hline Educación de la madre & $\begin{array}{c}-0,058^{\star \star \star} \\
(0,018)\end{array}$ & $\begin{array}{c}-0,068^{\star \star \star} \\
(0,023)\end{array}$ & $\begin{array}{l}-0,027 \\
(0,027)\end{array}$ & $\begin{array}{c}-0,081^{\star \star} \\
(0,039)\end{array}$ \\
\hline Padre ocupado & $\begin{array}{c}0,082 \\
(0,197)\end{array}$ & $\begin{array}{c}0,297 \\
(0,248)\end{array}$ & $\begin{array}{l}-0,106 \\
(0,246)\end{array}$ & $\begin{array}{c}0,186 \\
(0,469)\end{array}$ \\
\hline Padre desocupado & $\begin{array}{c}0,307 \\
(0,345)\end{array}$ & $\begin{array}{c}0,565 \\
(0,433)\end{array}$ & $\begin{array}{l}-0,082 \\
(0,482)\end{array}$ & $\begin{array}{c}0,592 \\
(0,626)\end{array}$ \\
\hline Madre ocupada & $\begin{array}{c}0,386^{\star \star *} \\
(0,132)\end{array}$ & $\begin{array}{l}0,448^{\star \star} \\
(0,186)\end{array}$ & $\begin{array}{c}0,270 \\
(0,192)\end{array}$ & $\begin{array}{l}0,443^{\star} \\
(0,245)\end{array}$ \\
\hline Madre desocupada & $\begin{array}{c}0,102 \\
(0,217)\end{array}$ & $\begin{array}{c}0,066 \\
(0,313)\end{array}$ & $\begin{array}{l}0,533^{\star} \\
(0,323)\end{array}$ & $\begin{array}{c}-0,939 \star \\
(0,527)\end{array}$ \\
\hline Menores de 5 años, varones & $\begin{array}{c}0,174 \\
(0,108)\end{array}$ & $\begin{array}{l}0,269^{\star} \\
(0,145)\end{array}$ & $\begin{array}{l}-0,058 \\
(0,171)\end{array}$ & $\begin{array}{c}0,247 \\
(0,183)\end{array}$ \\
\hline Menores de 5 años, mujeres & $\begin{array}{c}0,410^{\star \star \star} \\
(0,117)\end{array}$ & $\begin{array}{c}0,437^{\star \star \star} \\
(0,159)\end{array}$ & $\begin{array}{l}0,346^{*} \\
(0,191)\end{array}$ & $\begin{array}{c}0,437^{\star \star} \\
(0,194)\end{array}$ \\
\hline Asiste a la escuela & $\begin{array}{c}-1,091^{\star \star *} \\
(0,287)\end{array}$ & $\begin{array}{c}-1,587^{\star \star *} \\
(0,361)\end{array}$ & $\begin{array}{c}-1,083^{\star *} \\
(0,479)\end{array}$ & $\begin{array}{c}0,789 \\
(0,519)\end{array}$ \\
\hline Escuela pública & $\begin{array}{c}0,729 * * \star \\
(0,215)\end{array}$ & $\begin{array}{c}0,971^{\star \star \star} \\
(0,298)\end{array}$ & $\begin{array}{c}0,941^{* * *} \\
(0,356)\end{array}$ & $\begin{array}{c}0,099 \\
(0,384)\end{array}$ \\
\hline Programa Jefes de Hogar & $\begin{array}{c}-0,413^{\star \star} \\
(0,170)\end{array}$ & $\begin{array}{l}-0,229 \\
(0,226)\end{array}$ & $\begin{array}{c}-0,447^{\star} \\
(0,250)\end{array}$ & $\begin{array}{c}-0,888^{\star * \star} \\
(0,297)\end{array}$ \\
\hline Ordenada & $\begin{array}{c}-5,126^{\star \star \star} \\
(0,761)\end{array}$ & $\begin{array}{c}-7,367^{\star \star \star} \\
(1,115) \\
\end{array}$ & $\begin{array}{c}-4,739 \star \star \star \\
(1,158)\end{array}$ & $\begin{array}{c}-8,836^{\star \star \star} \\
(1,377)\end{array}$ \\
\hline Observaciones & 4808 & 4808 & & \\
\hline Pseudo-R2 & 0,169 & 0,146 & & \\
\hline
\end{tabular}

Nota: Error estándar entre paréntesis. ${ }^{\star \star \star} 1 \%,{ }^{\star \star} 5 \%,{ }^{\star} 1 \%$.

Fuente: Construcción propia con datos de la EanNA. 
Jorge A. Paz y Carolina Piselli

Cuadro A.2b. Determinantes de la actividad económica de niñas y adolescentes mujeres

\begin{tabular}{|c|c|c|c|c|}
\hline \multirow{2}{*}{ Variables independientes } & \multirow{2}{*}{ Trabaja } & \multicolumn{3}{|c|}{ MNL (coeficientes) } \\
\hline & & Mercado & Autoconsumo & Doméstica \\
\hline & $(1)$ & (2) & (3) & (4) \\
\hline Hogar con pobreza extrema & $\begin{array}{c}0,236 \\
(0,190)\end{array}$ & $\begin{array}{c}0,248 \\
(0,279)\end{array}$ & $\begin{array}{c}0,540 \\
(0,396)\end{array}$ & $\begin{array}{c}0,167 \\
(0,247)\end{array}$ \\
\hline Hogar pobre & $\begin{array}{c}0,125 \\
(0,165)\end{array}$ & $\begin{array}{c}0,071 \\
(0,262)\end{array}$ & $\begin{array}{c}0,323 \\
(0,345)\end{array}$ & $\begin{array}{l}0,116 \\
(0,211)\end{array}$ \\
\hline Número de privaciones & $\begin{array}{c}0,095 \\
(0,071)\end{array}$ & $\begin{array}{l}-0,145 \\
(0,111)\end{array}$ & $\begin{array}{c}0,330^{\star \star \star} \\
(0,115)\end{array}$ & $\begin{array}{l}0,143 \\
(0,091)\end{array}$ \\
\hline Edad del niño & $\begin{array}{l}0,323^{\star \star} \\
(0,146)\end{array}$ & $\begin{array}{c}0,653^{\star \star \star} \\
(0,221)\end{array}$ & $\begin{array}{c}0,148 \\
(0,307)\end{array}$ & $\begin{array}{l}0,409 * \star \\
(0,193)\end{array}$ \\
\hline Cuadrado de la edad del niño & $\begin{array}{l}-0,004 \\
(0,006)\end{array}$ & $\begin{array}{l}-0,014 \\
(0,009)\end{array}$ & $\begin{array}{l}-0,004 \\
(0,014)\end{array}$ & $\begin{array}{l}-0,007 \\
(0,008)\end{array}$ \\
\hline Reside en el NEA & $\begin{array}{c}-0,293^{\star \star} \\
(0,141)\end{array}$ & $\begin{array}{c}-0,465^{\star \star} \\
(0,218)\end{array}$ & $\begin{array}{l}-0,319 \\
(0,328)\end{array}$ & $\begin{array}{l}-0,191 \\
(0,176)\end{array}$ \\
\hline Reside en el NOA & $\begin{array}{c}0,109 \\
(0,129)\end{array}$ & $\begin{array}{c}0,002 \\
(0,187)\end{array}$ & $\begin{array}{c}0,047 \\
(0,298)\end{array}$ & $\begin{array}{c}0,183 \\
(0,168)\end{array}$ \\
\hline Reside en Mendoza & $\begin{array}{c}0,016 \\
(0,166)\end{array}$ & $\begin{array}{c}0,279 \\
(0,234)\end{array}$ & $\begin{array}{c}0,120 \\
(0,409)\end{array}$ & $\begin{array}{l}-0,272 \\
(0,239)\end{array}$ \\
\hline Reside en área rural & $\begin{array}{c}0,212 \\
(0,175)\end{array}$ & $\begin{array}{c}0,208 \\
(0,254)\end{array}$ & $\begin{array}{c}0,936^{\star * *} \\
(0,268)\end{array}$ & $\begin{array}{l}-0,151 \\
(0,240)\end{array}$ \\
\hline Edad del padre & $\begin{array}{c}0,004 \\
(0,004)\end{array}$ & $\begin{array}{l}-0,005 \\
(0,007)\end{array}$ & $\begin{array}{c}0,021^{\star \star *} \\
(0,008)\end{array}$ & $\begin{array}{c}0,004 \\
(0,005)\end{array}$ \\
\hline Edad de la madre & $\begin{array}{l}-0,007 \\
(0,005)\end{array}$ & $\begin{array}{l}0,006 \\
(0,008)\end{array}$ & $\begin{array}{l}-0,005 \\
(0,009)\end{array}$ & $\begin{array}{c}-0,017^{\star \star \star} \\
(0,006)\end{array}$ \\
\hline Educación del padre & $\begin{array}{l}-0,026 \\
(0,022)\end{array}$ & $\begin{array}{l}-0,006 \\
(0,030)\end{array}$ & $\begin{array}{c}0,016 \\
(0,065)\end{array}$ & $\begin{array}{c}-0,051^{\star} \\
(0,027)\end{array}$ \\
\hline Educación de la madre & $\begin{array}{c}-0,051^{\star \star \star} \\
(0,017)\end{array}$ & $\begin{array}{c}-0,071^{* * *} \\
(0,026)\end{array}$ & $\begin{array}{l}-0,031 \\
(0,037)\end{array}$ & $\begin{array}{c}-0,041^{\star} \\
(0,022)\end{array}$ \\
\hline Padre ocupado & $\begin{array}{l}-0,174 \\
(0,203)\end{array}$ & $\begin{array}{c}0,008 \\
(0,361)\end{array}$ & $\begin{array}{l}-0,534 \\
(0,386)\end{array}$ & $\begin{array}{l}-0,031 \\
(0,260)\end{array}$ \\
\hline Padre desocupado & $\begin{array}{c}-1,112^{\star \star \star} \\
(0,349)\end{array}$ & $\begin{array}{c}-1,154^{\star \star} \\
(0,568)\end{array}$ & $\begin{array}{c}-1,547^{\star \star \star} \\
(0,576)\end{array}$ & $\begin{array}{c}-0,808^{*} \\
(0,469)\end{array}$ \\
\hline Madre ocupada & $\begin{array}{c}0,504^{\star \star \star} \\
(0,135)\end{array}$ & $\begin{array}{c}0,525^{\star \star} \\
(0,218)\end{array}$ & $\begin{array}{c}0,651^{\text {** }} \\
(0,277)\end{array}$ & $\begin{array}{c}0,475^{\star \star \star} \\
(0,164)\end{array}$ \\
\hline Madre desocupada & $\begin{array}{c}0,090 \\
(0,287)\end{array}$ & $\begin{array}{c}0,298 \\
(0,419)\end{array}$ & $\begin{array}{c}0,701 \\
(0,545)\end{array}$ & $\begin{array}{l}-0,362 \\
(0,359)\end{array}$ \\
\hline Menores de 5 años, varones & $\begin{array}{c}0,354^{\star \star \star} \\
(0,096)\end{array}$ & $\begin{array}{c}0,450^{\star \star \star} \\
(0,137)\end{array}$ & $\begin{array}{c}0,399 * * \\
(0,175)\end{array}$ & $\begin{array}{l}0,277^{\star \star} \\
(0,117)\end{array}$ \\
\hline Menores de 5 años, mujeres & $\begin{array}{c}0,311^{\star \star \star} \\
(0,110)\end{array}$ & $\begin{array}{c}0,239 \\
(0,191)\end{array}$ & $\begin{array}{l}-0,189 \\
(0,232)\end{array}$ & $\begin{array}{c}0,479 * \star \star \\
(0,122)\end{array}$ \\
\hline Asiste a la escuela & $\begin{array}{c}-0,946^{\star \star \star} \\
(0,287)\end{array}$ & $\begin{array}{c}-0,889 * \star \\
(0,416)\end{array}$ & $\begin{array}{l}-0,308 \\
(0,565)\end{array}$ & $\begin{array}{c}-1,127^{\star \star \star} \\
(0,361)\end{array}$ \\
\hline Escuela pública & $\begin{array}{c}0,658^{\star \star \star} \\
(0,209)\end{array}$ & $\begin{array}{c}0,723^{\star \star} \\
(0,349)\end{array}$ & $\begin{array}{c}0,389 \\
(0,485)\end{array}$ & $\begin{array}{c}0,681^{\star \star \star} \\
(0,254)\end{array}$ \\
\hline Programa Jefes de Hogar & $\begin{array}{c}0,051 \\
(0,165)\end{array}$ & $\begin{array}{c}0,565^{\star \star} \\
(0,243)\end{array}$ & $\begin{array}{l}-0,397 \\
(0,352)\end{array}$ & $\begin{array}{l}-0,201 \\
(0,205)\end{array}$ \\
\hline Ordenada & $\begin{array}{c}-3,873^{\star \star \star} \\
(0,823) \\
\end{array}$ & $\begin{array}{c}-7,660^{* * *} \\
(1,379) \\
\end{array}$ & $\begin{array}{c}-5,448^{\star \star \star} \\
(1,569) \\
\end{array}$ & $\begin{array}{c}-4,546^{* \star \star} \\
(1,131) \\
\end{array}$ \\
\hline Observaciones & 4651 & 4651 & & \\
\hline Pseudo-R2 & 0,165 & 0,152 & & \\
\hline
\end{tabular}

